\title{
Sobre a pesquisa Educação e Relações Étnico-Raciais
}

\author{
Paulo Vinicius Baptista da Silva* \\ Kátia Regis** \\ Shirley Aparecida de Miranda ${ }^{* * *}$
}

O projeto de Educação das Relações Étnico-Raciais: o estado da arte teve seu início como proposição do Grupo de Trabalho em Educação e Relações Étnico-Raciais (GT 21) da Associação Nacional de Pós-Graduação e Pesquisa em Educação (ANPED). No trâmite de sua aprovação inicial envolveu a ABPN (Associação Brasileira de Pesquisadores Negros) e o CONNEAB (Consórcio Nacional de Núcleos de Estudos Afro-Brasileiros) e foi aprovado para financiamento com um ano de execução pela SECADI/MEC (Secretaria de Educação Continuada, Alfabetização, Diversidade e Inclusão). No decorrer da pesquisa houve apoio institucional da Universidade Federal de Minas Gerais (UFMG), Universidade Federal do Maranhão (UFMA) e Universidade Federal do Paraná (UFPR) e contou com aporte de financiamentos complementares, especialmente de bolsas de iniciação científica do NEAB - UFPR do Programa Institucional de Apoio à Inclusão Social - Pesquisa e Extensão Universitária da Fundação Araucária de Apoio Científico e Tecnológico do Estado do Paraná, de bolsas IC CNPQ e CAPES da UFPR, da UFMG, da UFMA e da UFF.

O projeto de realizar uma ampla síntese do conhecimento produzido no Brasil sobre Educação das Relações Étnico-Raciais (ERER) se relaciona com o aumento de produção na área, assim como com a estruturação do GT 21 na ANPED e com a aprovação do Artigo 26A da LDB (modificado pelas Lei 10.639/03 e 11.645/08). Tem também o objetivo de preencher uma lacuna nesta área que não dispõe de um estado da arte como outras áreas de pesquisa em

* Universidade Federal do Paraná. Pesquisador do Núcleo de Estudos Afro-Brasileiros (NEAB-UFPR), Programa de Pós-Graduação em Educação. Curitiba, Paraná, Brasil. E-mail: pauloviniciusufpr@gmail.com. ORCID: https://orcid.org/0000-0001-9207-2439

${ }^{* *}$ Universidade Federal do Maranhão. Coordenadora da Licenciatura Interdisciplinar em Estudos Africanos e Afro-Brasileiros. São Luís, Maranhão, Brasil. E-mail: katia_educ@yahoo.com. br. ORCID: https://orcid.org/0000-0002-4104-1963

*** Universidade Federal de Minas Gerais. Faculdade de Educação. Integrante da coordenação do Programa Ações Afirmativa. Coordenadora do Grupo de Pesquisas sobre Quilombos e Educação. E-mail: mirandashirley48@gmail.com. ORCID: https://orcid.org/0000-0001-8312-2262 
educação no Brasil (ROCHA, SILVA FILHO, STRENZEL, 2001; BARRETO e PINTO, 2001; ANDRÉ, 2002; HADDAD, 2002; SPOSITO, 2002; LOPES e MACEDO, 2006; BRZEZINSKI, 2014).

O levantamento de artigos, teses e dissertações foi realizado no segundo semestre de 2015, pelas equipes do NEAB-UFPR, Licenciatura em Estudos Africanos e Afro-Brasileiros e NEAB-UFMA. Foi também realizado um levantamento de livros produzidos pelos NEABs por equipe da UFMG.

Para as revistas, uma primeira definição necessária era selecionar os periódicos que são da área de educação. A partir da consulta das planilhas de avaliação qualis de 2012, de periódicos indexados pela EDUBASE da Unicamp, um dos principais indexadores da área de educação no Brasil, que à época permitiu acesso on-line (não conseguimos acesso via web a listagem do outro indexador importante da área, o repositório Bibliografia Brasileira de Educação do INEP) e dos relatórios de reuniões e uma publicação do Fórum de Editores de Periódicos da Área de Educação (FEPAE) da ANPED, chegou-se a um total de 266 periódicos publicados entre 2003 e 2014. As buscas foram realizadas diretamente nos sites das revistas. Para o trabalho de busca de artigos foi mobilizada uma equipe de 11 bolsistas de iniciação científica da UFPR.

Em seguida, uma série de informações foram extraídas dos artigos e dispostas em planilha excel com informações nas colunas. Foi realizada, pela coordenação, a leitura dos títulos e resumos de 652 artigos que haviam sido recuperados. Os artigos foram inicialmente agrupados em 19 diferentes categorias. Diversos artigos foram considerados como não tomando parte da área de educação das relações étnico-raciais e foram excluídos. Os artigos da categoria "educação indígena" foram separados, em função da não existência de especialistas desta área na equipe de pesquisa. Restaram então 488 artigos.

A busca de teses e dissertações estava sendo realizada pela equipe de pesquisa da UFMA, de forma paralela. Inicialmente foi planejada para ser realizada no Banco de Teses da CAPES, que é um repositório de resumos que deveria ser completo. No entanto, o referido banco de dados esteve em manutenção durante o período de realização das buscas e foi colocado no ar de forma limitada, com acesso aos resumos publicados apenas de 2011 e 2012. A busca foi então realizada pela via da página web de cada um dos programas de pós-graduação e cursos de mestrado acadêmico da área de educação. Utilizando os mesmos descritores, foram localizadas 876 entradas e foram selecionadas 631 teses e dissertações para análise. As informações de cada categoria foram transpostas para planilhas excel.

As equipes de pesquisa envolveram diversas Universidades, programas de pós-graduação em educação e NEABS. As equipes no período das buscas foram compostas por: 
UFPR: Paulo Vinicius Baptista da Silva; Lucimar Rosa Dias; Valeria Milena Ferreira; Rosa Amália Espejo Trigo (pós-doc); doutoranda Débora Cristina de Araújo; doutorando Wellington Oliveira dos Santos; doutoranda Rita de Cássia Alcaraz; IC Daiane da Silva Vasconcelos; IC Pietra Izabela Barbosa; IC Thalita Carlota Arica; IC Roberta Regina Chaves Veloso; IC Cintia Raquel Moreira Ribeiro; IC Edlonson de Oliveira; IC Cleverton Quadros; IC Antonio Anderson Ribeiro; IC Maria Leonora Pereira Cabral; IC Isabela Camila dos Santos; IC Jarson Brenner Borges; IC Lucas de Lima Schmoller.

UFMA: Kátia Regis; Marcelo Pagliosa; Doutorando Richard Christian Pinto dos Santos; Profa. Ma. Grace Kelly Sobral Souza.

UFMG: Shirley Aparecida de Miranda; Rodrigo Ednilson de Jesus; Doutoranda Carmen Regina Gonçalves; Mestranda Suelen Alves dos Santos; IC Franz Galvão Piragibe; IC Silvia Maria de Miranda.

A equipe da UFPR havia realizado a leitura de todos os títulos e resumos e agrupado os artigos em 19 categorias, ao passo que a equipe da UFMA leu os títulos e resumos das teses e dissertações e as organizou em 18 categorias. Boa parte das categorias eram coincidentes, o que facilitou a organização em um mesmo grupo de categorias. Algumas categorias foram incorporadas ou agrupadas, de forma a chegar a um número de 13, a seguir agrupadas em 11 categorias, mesmo número de doutores que compunham a equipe naquele momento. Tal organização por temas aproxima mais esta pesquisa das coordenadas por Morosini (2001), Sposito (2002) e Haddad (2002), entre as pesquisas da série de estados da arte em educação mantida pelo INEP. Essa organização do universo de publicações em categorias em mesmo número de pesquisadores/as tinha o propósito de constituir o corpus a ser analisado de forma a não deixar de fora nenhuma publicação do universo identificado. Posteriormente uma das categorias foi desdobrada; livros didáticos e literatura inicialmente estavam agrupados, mas ao final foram analisados de forma independente, com a conclusão do doutorado e continuidade de participação da Dra. Débora Cristina de Araújo como pesquisadora da equipe.

Muitos dos artigos, das teses e das dissertações abordam concomitantemente mais de um tema. Tais textos poderiam ser classificados em mais de uma categoria, mas a opção foi classificar cada artigo em uma única categoria (a mais proeminente pela leitura de título, resumo e palavras-chave), em função do grande número de publicações a serem analisadas. O quadro 1 a seguir apresenta os números de publicações selecionadas para análise, por categoria: 
QUADRO 1 - NÚMERO DE TESES, DE DISSERTAÇÕES E DE ARTIGOS SELECIONADOS PARA ANÁLISE, POR CATEGORIA

\begin{tabular}{|c|c|c|}
\hline CATEGORIA & $\begin{array}{l}\text { NÚMERO DE TESES } \\
\text { E DISSERTAÇÕES }\end{array}$ & $\begin{array}{l}\text { NÚMERO DE } \\
\text { ARTIGOS }\end{array}$ \\
\hline CURRÍCULO & 63 & 37 \\
\hline AÇÕES AFIRMATIVAS & 69 & 94 \\
\hline FORMAÇÃO DE PROFESSORES & 28 & 51 \\
\hline LIVRO DIDÁTICO & 28 & 11 \\
\hline LITERATURA & 14 & 27 \\
\hline IMPLEMENTAÇÃO DA LEI No $10.639 / 2003$ & 46 & 65 \\
\hline $\begin{array}{l}\text { RELAÇÕES ÉTNICO- RACIAIS NAS } \\
\text { INSTITUIÇÕES EDUCACIONAIS }\end{array}$ & 58 & 38 \\
\hline $\begin{array}{l}\text { IDENTIDADE NEGRA E } \\
\text { MULTICULTURALISMO }\end{array}$ & 103 & 56 \\
\hline HISTÓRIA AFRO-BRASILEIRA & 35 & 31 \\
\hline $\begin{array}{l}\text { MOVIMENTO NEGRO E EDUCAÇÃO } \\
\text { RELIGIOSIDADE } \\
\text { JUVENTUDE NEGRA }\end{array}$ & 65 & 29 \\
\hline QUILOMBOS & 48 & 24 \\
\hline $\begin{array}{c}\text { CULTURA: OUTROS CURRÍCULOS } \\
\text { OUTRAS PEDAGOGIAS }\end{array}$ & 41 & 31 \\
\hline TOTAL & 598 & 494 \\
\hline
\end{tabular}

A seguir, os artigos, teses e dissertações de cada uma das 12 categorias passaram por uma nova leitura de resumos e, em casos específicos, de textos completos, para extrair novas informações que dispostas em arquivo excel. Os dados que foram sendo lançados em colunas específicas na sequência, organizados em tabelas simples de frequência, com uso do software SPSS, o que possibilitou uma primeira visão panorâmica de diversos aspectos da produção em cada uma das categorias. Paralelamente a este trabalho os artigos foram impressos e disponibilizados aos pesquisadores/as que realizaram a leitura na íntegra para a realização de análises mais qualitativas. Cada pesquisador/a responsável pela área de conhecimento realizou uma análise da produção de sua respectiva categoria, contando com o auxílio de um/a bolsista de iniciação científica e podendo contar, conforme disponibilidade de equipes locais, com o auxílio de outros/as membros/as convidados/as. Em cada um dos 12 eixos/categorias foi preparado um capítulo contendo a análise da produção em artigos, e de teses e dissertações, seguindo um roteiro: panorama do eixo, temas recorrentes, temas emergentes, lacunas, sugestões para a Educação das Relações Étnico-Raciais e síntese conclusiva. 
GRÁFICO 1 - ANO DE PUBLICAÇÃO DOS ARTIGOS

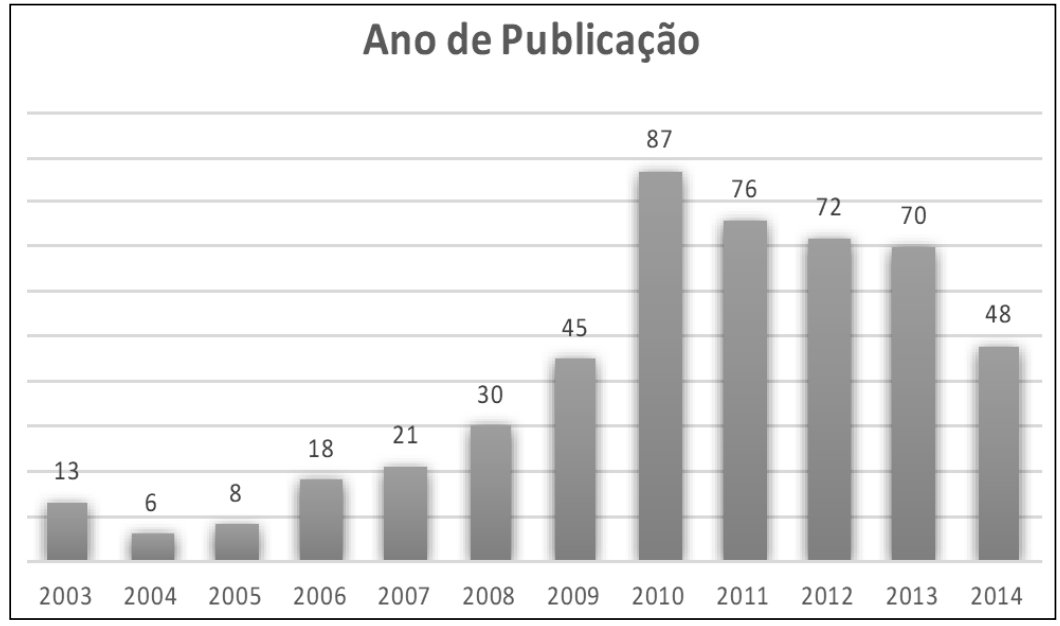

FONTE: Pesquisa Educação e Relações Étnico-Raciais: O Estado da Arte, 2017.

Os artigos recuperados para análise apresentaram um crescente de publicações ao longo dos anos posteriores a 2003, tendo como ápice 2010, mantendo-se alta nos anos seguintes, mas com diminuição gradativa nos anos e baixa em 2014 .

GRÁFICO 2 - ANO DE PUBLICAÇÃO DAS TESES E DISSERTAÇÕES

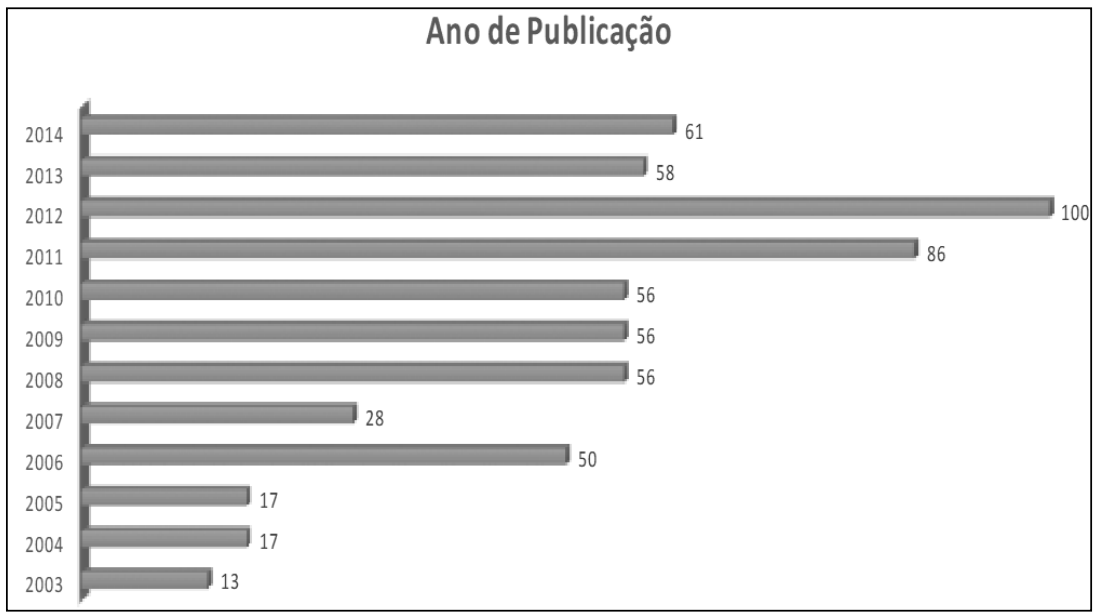

FONTE: Pesquisa Educação e Relações Étnico-Raciais: O Estado da Arte, 2017. 
As teses e dissertações tiveram uma distribuição similar, com crescimento até o ano de 2012 e diminuição em 2013 e 2014. Este conjunto de 494 artigos e 598 teses e dissertações possibilitou uma série de análises nas 12 categorias.

Os artigos que compõem o dossiê a seguir são parte das análises de sete das referidas 12 categorias de distribuição das publicações da pesquisa. Cumprem o objetivo de realizar um balanço sistematizado das publicações em ERER, contando ainda com uma análise de colaboradores de Moçambique.

$\mathrm{O}$ artigo que inicia o dossiê, Lingua e cultura em contexto multilingue: um olhar sobre o sistema educativo em Moçambique, de Amélia Francisco F. da C. Lemos, realiza uma revisão bibliográfica sobre políticas linguísticas e educação em Moçambique. O texto analisa as propostas de educação num contexto multilíngue e propõe o uso do amplo repertório linguístico de Moçambique como recurso a ser explorado pela educação.

O artigo Currículo e Relações Étnico-Raciais: o Estado da Arte de Kátia Evangelista Regis e Guilherme Basilio, analisa 38 artigos, 13 teses e 50 dissertações. Por meio da subcategorização, refletem sobre as temáticas recorrentes na produção investigada e apresentam caminhos abertos para pesquisas futuras. Ao final, destacam as recomendações dos trabalhos para a implementação da Lei $\mathrm{n}^{\circ} 10.639 / 2003$, tais como: formação inicial e formação continuada dos(as) professores(as); produção e socialização de materiais didáticos sobre a História e Cultura Africana e Afro-Brasileira; inclusão de disciplinas e conteúdos sobre o tema nos currículos das Instituições de Ensino Superior (IES); inserção da História e Cultura Africana e Afro-Brasileira nos Projetos Político-Pedagógicos (PPPs) das instituições educacionais; maior aporte de recursos financeiros e a ampliação e consolidação do intercâmbio entre as universidades brasileiras e as de diferentes países do Continente Africano para o desenvolvimento de pesquisas conjuntas que ofereçam novas perspectivas epistemológicas para possibilitar a implementação da Lei n ${ }^{\circ}$ 10.639/2003.

Débora Cristina de Araújo no artigo As relações étnico-raciais na Literatura Infantil e Juvenil analisa 13 teses e dissertações, estabelecendo duas categorias: a "análise literária", reunindo os estudos que investigaram uma ou mais obras de um mesmo autor e cuja característica em comum é a interface com contextos históricos e sociológicos, em especial do passado; e a "escolarização da literatura", agrupando as pesquisas que, no contexto escolar, investigaram a presença, leitura e interpretação de obras literárias infantis e juvenis. Via de regra, os estudos indicaram um consenso sobre mudanças, ainda que diminutas, na representação de personagens negras a partir de publicações literárias mais recentes, embora negras e negros ainda sejam minoria como personagens no universo literário infantil e juvenil de modo geral. 
Em Livro didático, educação e relações étnico-raciais: o Estado da Arte, Tania Mara Pedroso Muller discute os resultados de 29 dissertações e teses sobre a temática que, apesar de apontarem mudanças nos LDs - Livros didáticos analisados, os autores concordam com a permanência de representações estereotipadas da população negra, quando destacam o uso de iconografias relacionadas a miséria, violência, escravidão, reduzidas muitas vezes à folclorização.

O artigo Formação de Professores e relações étnico-raciais (2003-2014): produção em teses, dissertações e artigos, em perspectiva, de Wilma de Nazaré Baía Coelho tem como objeto a ampliação sobre a temática expressa em 52 artigos, 8 teses e 22 dissertações defendidas no período. Entre as conclusões, infere que essa literatura especializada transformou questões em aportes, perspectivas, temas e objetos, conformou um campo de pesquisa, entre as diversas recorrências temáticas e de objetos. É necessário caminhar, todavia, no campo das práticas - a questão do racismo e seus desdobramentos reclama reflexões que entendam sua gênese e proliferação. Rever currículos, repensar pesquisas, problematizar aportes, criticar lugares consagrados, desafiar os cânones são algumas das dimensões deste desafio.

No artigo Educação das Relações Étnico-Raciais em instituições escolares Petronilha Beatriz Gonçalves e Silva analisou 38 artigos, 7 teses e 51 dissertações sobre resultados e experiências em estabelecimentos a maioria de ensino fundamental, anos iniciais, mas também de educação infantil e EJA. Analisou os conceitos de racismo e etnocentrismo presentes nestas publicações. As dissertações e teses analisadas investigaram problemáticas, relacionadas a: - culturas silenciadas ou "simplificadas" no currículo escolar; - representações de raça - negros, brancos; - representações de gênero e de branquitude, negritude; - experiências de racismo, autodeclaração a respeito de raça/cor, em anos iniciais de escolarização; - preconceitos em livros didáticos: persistência de representação estereotipada de negros; - desempenho escolar: comparação entre negros e brancos; - escola reprodutora, fomentadora de valores.

Em Políticas Afirmativas na pesquisa educacional, Paulo Vinicius Baptista da Silva e Carolina dos Anjos de Borba discutem os resultados de 86 artigos publicados e discute as mudanças de temas principais ocorridas ao longo do período 2003-2014, passando a apresentar uma maioria de análises de resultados de universidades específicas, que apresentam resultados favoráveis de diferentes formas de políticas afirmativas (cotas raciais, cotas para escola pública, bônus, PROUNI), mas tem pouco diálogo e limitada possibilidade de comparação dos dados.

Shirley Aparecida Miranda em Quilombos e Educação: identidades em disputa discutem os dilemas da constituição das identidades quilombolas em interface com a educação escolar. Verificou-se a adoção de uma concepção 
de identidade quilombola construída em meio a lógicas de funcionamento do racismo e aos dilemas do pertencimento a um determinado território material e simbólico inserido em disputas econômicas.

Compõem ainda o dossiê as Resenhas das obras Entre Brasil e África: construindo conhecimento e militância de Petronilha Beatriz Gonçalves e Silva, Belo Horizonte: Mazza, 2011, por Wilker Solidade (PPGE-UFPR) e $O$ Movimento Negros Educador. Saberes Construídos nas Lutas por Emancipação de Nilma Lino Gomes, Petrópolis: Vozes, 2017, por Maysa Ferreira da Silva (PPGE-UFPR).

\section{REFERÊNCIAS}

ANDRÉ, M. (Org.). Formação de professores no Brasil (1990-1998). Brasília: MEC/ Inep/Comped, 2002.

BARRETO, E. S. S.; PINTO, R. P. (Coord.). Avaliação na Educação Básica (1990-1998). Brasília: MEC/Inep/Comped, 2001.

BRZEZINSKI, I. Formação de profissionais da educação (2003-2010). Brasília: INEP, 2014.

HADDAD, S. (Coord.). Educação de jovens e adultos (1986-1998). Brasília: MEC/ Inep/Comped, 2002.

LOPES, A. C.; MACEDO, E. (Coord.). Currículo da educação básica (1996-2002). Brasília: MEC/INEP, 2006.

MOROSINI, M. C. (Coord.). Educação Superior em Periódicos Nacionais (1968-1995). Brasília: MEC/Inep/Comped, 2001.

ROCHA, E. A. C.; SILVA FILHO, J. J.; STRENZEL, G. R. (Coord.). Educação Infantil (1983-1996). Brasília: MEC/Inep/Comped, 2001.

SPOSITO, M. P. (Coord.). Juventude e escolarização (1980-1998). Brasília: MEC/Inep/ Comped, 2002.

Texto recebido em 29 de dezembro de 2017.

Texto aprovado em 13 de março de 2018. 